\title{
Questões econômicas
}

e gerenciais envolvidas

na adoção e manutenção

de sistemas de integração

lavoura-pecuária

\section{Economic and management issues involved in the adoption and maintenance of integrated crop-livestock systems}

\begin{abstract}
Resumo
Os profissionais envolvidos nas cadeias de produção animal e vegetal se deparam com um cenário atual de contradições. De um lado, o aumento pela demanda de alimentos, de outro, as pressões sociais que questionam o modo como é conduzida a produção. Neste contexto, os sistemas integrados podem ser uma importante estratégia. A integração lavoura-pecuária (ILP) consiste na implantação de diferentes sistemas produtivos para a produção animal e vegetal na mesma área, em plantio consorciado, sequencial ou rotacional. Os benefícios mais divulgados em relação aos sistemas de ILP são os agronômicos ou produtivos, que são consequência da melhoria da qualidade do solo e maior controle de pragas. Contudo, para que os sistemas de ILP sejam adotados em escala comercial, representando de fato uma alternativa para a produção de alimentos, é necessário que a ciência aborde também questões econômicas e gerenciais envolvidas na adoção e manutenção dos sistemas de ILP.
\end{abstract}

\section{Abstract}

Professionals involved in animal and plant production chains are currently confronted with a scenario of contradictions. There is a growing demand for food, on the other hand, social pressures question how food is produced. Within this context, integrated production systems could be an important strategy. Integrated crop-livestock systems (ICL) consists of the implementation of different systems for animal and agricultural production in the same area, planted concurrently, sequentially or in rotation. The most reported advantages of ICL systems are agronomic or productive benefits, which are the result of improved soil quality and better pest control. However, to implement ICL systems on large scale, representing an actual alternative for food production, scientific research must address the economic and management issues involved in the adoption and maintenance of these systems. 
Gabriela Geraldi Mendonça ${ }^{1}$

Jeferson Garcia Augusto ${ }^{2}$

Pedro Miele Bonacim²

Leonardo Sartori Menegatto ${ }^{2}$

Flávia Fernanda Simili²

Augusto Hauber Gameiro ${ }^{1}$
Avenida Segismundo Mangoline, 316, Jardim Boa Vista,

Guariba/SP, CEP: 14840-000

曰 gabigeraldi@hotmail.com

\section{Palavras-chave}

Planejamento agropecuário.

Produção de alimentos. Sistemas alternativos.

\section{Keywords}

Agricultural planning. Food production. Alternative systems.

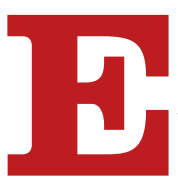

m meados da década de 1960, no contexto mundial da Revolução Verde, o aumento da produtividade de culturas vegetais e animais no Brasil e no mundo foi pautado na especialização dos sistemas produtivos (monocultivo). A alteração genética de sementes e alimentos, a utilização de energias não renováveis e o intenso uso de máquinas e implementos agrícolas, bem como de fórmulas químicas para aplicação de nutrientes e combate a pragas, foram estratégias para o aumento da produtividade agropecuária.

O equilíbrio entre demanda crescente por alimentos e conservação de recursos é um dos maiores desafios enfrentados pela sociedade atualmente (ANSELL et al., 2016). Surge a necessidade, portanto, de que atores relevantes neste cenário, como instituições de pesquisa, iniciativa privada e serviços de extensão, definam estratégias e validem alternativas para esse contexto.

Neste cenário, sistemas de integração lavoura-pecuária (ILP) apresentam um delineamento promissor para sistemas produtivos que devem racionalizar recursos naturais sem perder eficiência, assegurando o incremento da produção agropecuária, otimizando o uso de áreas agricultáveis, permitindo o aproveitamento de tecnologias e promovendo melhorias das características do solo. 
Macedo (2009) refere que a ILP consiste na implantação de diferentes sistemas produtivos de grãos, fibras, carne, leite e agroenergia na mesma área, em plantio consorciado, sequencial ou rotacional, objetivando efeitos sinérgicos entre os componentes do agroecossistema.

Os benefícios mais citados dos sistemas de ILP são: melhoria dos atributos físicos, químicos e biológicos do solo, ciclagem de nutrientes entre as culturas, acúmulo de matéria orgânica, diminuição do risco de pragas e plantas invasoras e possível mitigação de gases do efeito estufa (LEMAIRE et al., 2014; SALTON et al., 2014). Tais benefícios são imprescindíveis para que a produtividade das culturas seja competitiva quando comparada aos sistemas de monocultivo.

Postula-se a hipótese de que a divulgação apenas dos benefícios biológicos e produtivos não é suficiente para encorajar a mudança, sendo necessária a difusão de mais informações, do ponto de vista econômico e gerencial, que subsidiem a tomada de decisão do produtor rural. Explorar a diversidade de combinações entre espécies vegetais e animais e as possíveis estratégias de rotação, sucessão ou consórcio, conseguindo quantificar custos e receitas, parece ser um passo importante para que os sistemas de ILP se consolidem no cenário produtivo brasileiro.

As experiências compartilhadas neste ensaio são baseadas em um protejo chamado "Impacto ambiental, produtividade e viabilidade econômica de sistemas de monocultivo e integrado de lavoura-pecuária", financiado pela Fundação de Amparo à Pesquisa do Estado de São Paulo (Fapesp). Trata-se da implantação de sistemas de ILP de milho-grão e capim-marandu desenvolvidos no Centro Avançado de Pesquisa em Bovinos de Corte de Sertãozinho, pertencente ao Instituto de Zootecnia da Agência Paulista de Tecnologia dos Agronegócios.

O objetivo deste ensaio é descrever aspectos econômicos dos sistemas de ILP e eventuais entraves para sua adoção.

\section{Aspectos econômicos de sistemas de ILP}

Martha Júnior, Alves e Contini (2011) destacam que o principal questionamento a ser levantado é se, após os benefícios biológicos e produtivos obtidos pelos sistemas integrados, os ganhos econômicos levam à tomada de decisão para a especialização dos sistemas agropecuários ou para sua diversificação. Os benefícios econômicos potenciais dos sistemas integrados, citados na literatura, são a economia de escopo e a redução de risco pela diversificação.

Gao e Featherstone (2008) referem que a economia de escopo reflete a redução no custo unitário, quando mais de um produto é produzido por uma mesma empresa. Extrapolando a questão conceitual, é necessário entender como exatamente funciona a economia de escopo, identificando as fontes que permitem que os custos unitários de produção sejam reduzidos dentro dos sistemas integrados. Uma das principais hipóteses acerca das fontes da economia de escopo é a existência de insumos compartilháveis entre as culturas integradas, sendo os mais citados: infraestrutura, maquinários e implementos, mão de obra e benefícios agronômicos e ambientais obtidos a partir da integração das culturas (GAMEIRO; ROCCO; CAIXETA FILHO, 2016).

A terra, ou seja, a área utilizada para a produção, será compartilhada, já que esse é um dos princípios dos sistemas de ILP. Galpões e demais estruturas físicas necessárias para abrigar insumos também podem ser utilizadas em ambas as culturas. Caso se opte por armazenar grãos na fazenda, estruturas de armazenamento, como silos, talvez exijam maior especificidade.

O maquinário também pode ser um tipo de insumo compartilhado, a depender das culturas integradas. De maneira genérica, tratores e implementos para aplicação de produtos fitossanitários e adubos serão semelhantes em propriedades destinadas à produção vegetal ou animal. O maquinário destinado ao plantio das culturas é um item mais específico, havendo opção, entretanto, de que um mesmo implemento seja utilizado em duas culturas. Por exemplo, no caso de sistemas de ILP que visam o plantio da cultura de milho e de capim, existem implementos que tornam possível a implantação simultânea de ambas as culturas.

Adicionalmente, a mão de obra também pode ser encarada como um insumo compartilhável dentro de um sistema que integre lavoura e pecuária, desde que esforços sejam despendidos para isso. A mão de obra destinada às culturas vegetais, em geral, é mais especializada, acostumada a lidar rotineiramente com tecnologia e prazos. Já os profissionais responsáveis da pecuária extensiva apresentam menor domínio de recursos tecnológicos, uma vez que os animais de tração, como cavalos, são sua principal "ferramenta" de trabalho. Assim, é possível que haja certa resistência inicial dos profissionais responsáveis pelo monocultivo vegetal ou animal em dedicar-se aos sistemas integrados, sendo necessária, portanto, sua capacitação para ambos os sistemas.

Entretanto, utilizando os exemplos acima citados, torna-se intuitiva a afirmação de que instalações físicas, maquinários e mão de obra podem ser compartilhados até determinados limites, que se referem principalmente à quantidade produzida e ao tamanho do sistema de produção. Isso justifica a necessidade de maiores estudos do ponto de vista econômico, mais precisamente de como a economia de escopo se relaciona diretamente aos sistemas integrados. 

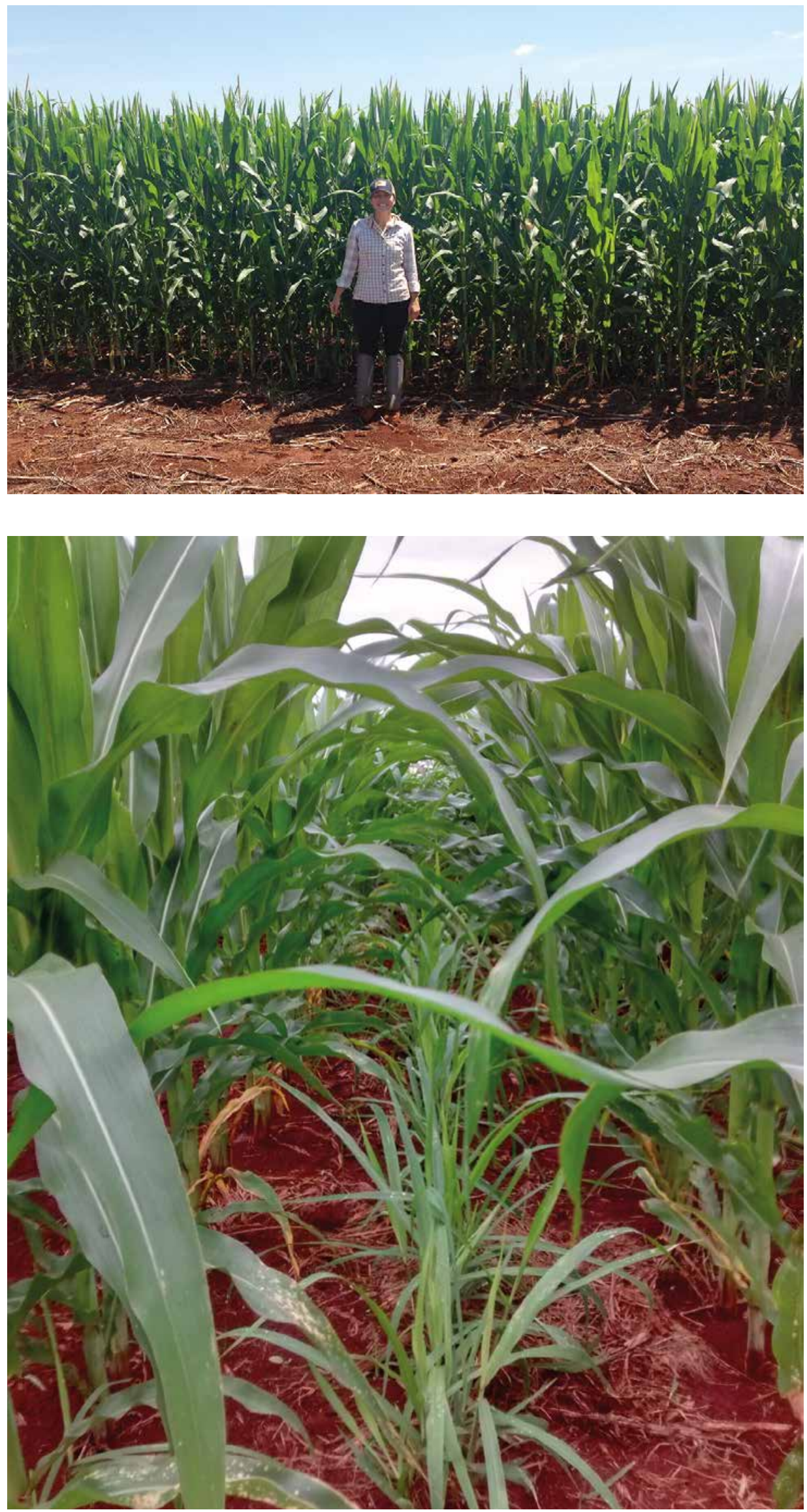

Figura 1 - Sistema de monocultivo de milho para produção de grão

Fonte: Acervo do autor.
Figura 2 - Sistema integrado: capim-marandu crescendo na entrelinha do milho. Fonte: Acervo do autor. 
A diversificação representa um dos recursos mais citados na literatura acadêmica e técnica para a "proteção" contra riscos nas empresas rurais, representando um tipo de autonomia diante das vulnerabilidades do setor primário. Ao assumir uma nova cultura em um sistema de produção, a empresa rural busca se prevenir de riscos representados pelo monocultivo (COIMBRA; PERINA; FAUSTO, 2015), que são, principalmente, questões climáticas desfavoráveis ou pragas que comprometam a produção e preços desfavoráveis ou flutuações no mercado de commodities. Além disso, o maior número de culturas diminui as variações da renda líquida anual da propriedade, o que reduz o impacto econômico pelo surgimento de crises no setor.

Para que a diversificação seja de fato estratégica, o que se espera é que tanto características intrínsecas das culturas produzidas - como condições climáticas, pragas e doenças e demais fatores que interfiram na produtividade - quanto características extrínsecas - como volatilidade de preços de mercado - sejam influenciadas de maneiras distintas. Assim, caso algum fator prejudique a produção ou venda de um dos produtos, espera-se que o outro seja fonte de receita, protegendo o produtor de prejuízos financeiros.

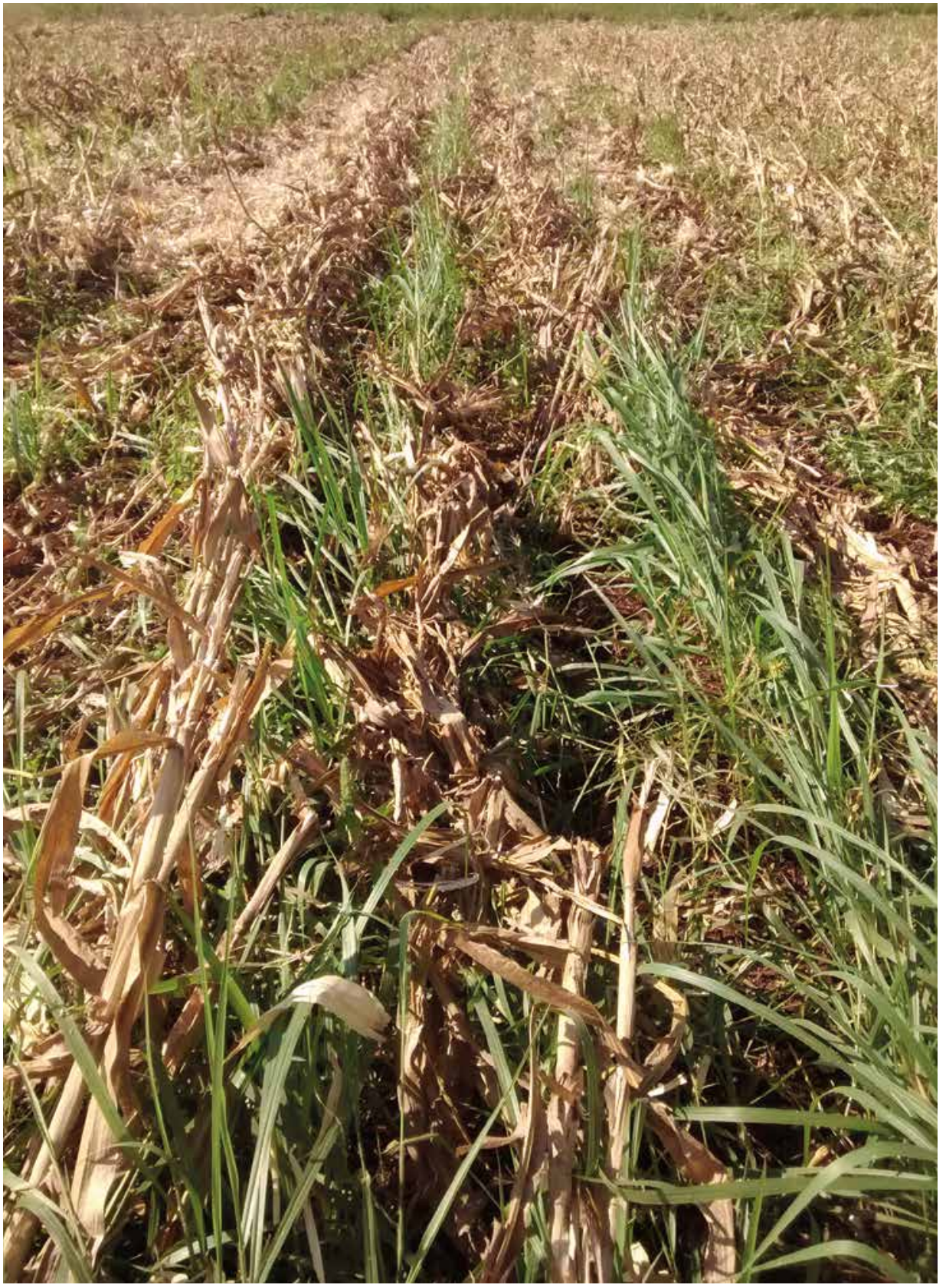

Figura 3 - Sistema integrado: após a colheita do milho, é hora de esperar a formação do pasto, para a entrada dos animais no sistema. Fonte: Acervo do autor 
Considerações acerca dos entraves para a adoção dos sistemas de ILP

A opção entre as modalidades de integração dependerá de fatores externos - como padrões climáticos, preços de mercado, estabilidade política, evolução tecnológica -, bem como de fatores internos - como características do solo e recursos naturais disponíveis. As diversas possibilidades de combinações de espécies forrageiras, culturas anuais e arranjos estruturais determinarão as interações entre os componentes e o manejo específico nos sistemas de ILP. Logo, pode-se concluir que, embora a vasta opção em termos de culturas a serem integradas seja um ponto positivo, há a dificuldade de se conseguir abordar e administrar os diversos tipos de delineamentos possíveis para um sistema de produção integrado.

Migrar de sistemas de monocultura para sistemas integrados exige mão de obra capacitada, domínio de novas tecnologias e investimentos em infraestrutura, bem como capacidade gerencial e conhecimento de novos tipos de mercado. Existem restrições estruturais e tecnológicas para que empresas rurais especializadas no monocultivo passem a atuar em sistemas integrados. A maior demanda por capital e para a aquisição e/ou manutenção de animais uma vez que os sistemas integrados exigem taxas de lotação elevadas e insumos associados aos dois produtos finais - pode ser citada como principal restrição, do ponto de vista econômico, para a ampla adoção dos sistemas integrados. As dimensões continentais do país não podem ser ignoradas, ou seja, é importante que a investigação acerca dos sistemas integrados seja geograficamente ampla a fim de demonstrar aspectos positivos e negativos dessa adoção em diferentes regiões produtoras.

Antes de pensar no que é necessário para a adoção de um sistema integrado, é preciso levar em consideração que há dois tipos de visões possíveis para essa discussão: a visão do agricultor e a visão do pecuarista. Os agricultores estão mais habituados, em sua rotina, com a utilização de tecnologias, como maquinários modernos, bem como com o gerenciamento de informações cruciais para seu negócio e com preços de commodities no mercado interno e externo. Já os pecuaristas, de maneira geral, estão habituados a práticas mais extensivas, com utilização restrita de maquinário e mão de obra.

No caso de um agricultor que desejasse integrar a pecuária em seu sistema produtivo, a primeira decisão seria quanto ao objetivo a ser atingido. Considerando a escolha pela pecuária de corte, a próxima decisão seria a categoria animal, considerando vantagens e facilidades do mercado regional (compra e venda de insumos e produto final, por exemplo). Há indícios de que a recria é a categoria animal mais fácil para quem inicia a atividade (ALMEIDA, et al., 2015).

$\mathrm{O}$ aspecto da mão de obra também deve ser considerado. Seria necessário pessoal habilitado à montaria, bem como alguém capacitado para orientações sobre manejo de pastagens e manejo animal. A infraestrutura da propriedade também precisaria ser alterada, com a construção de cercas, reservatórios de água, cochos e curral para manejo.

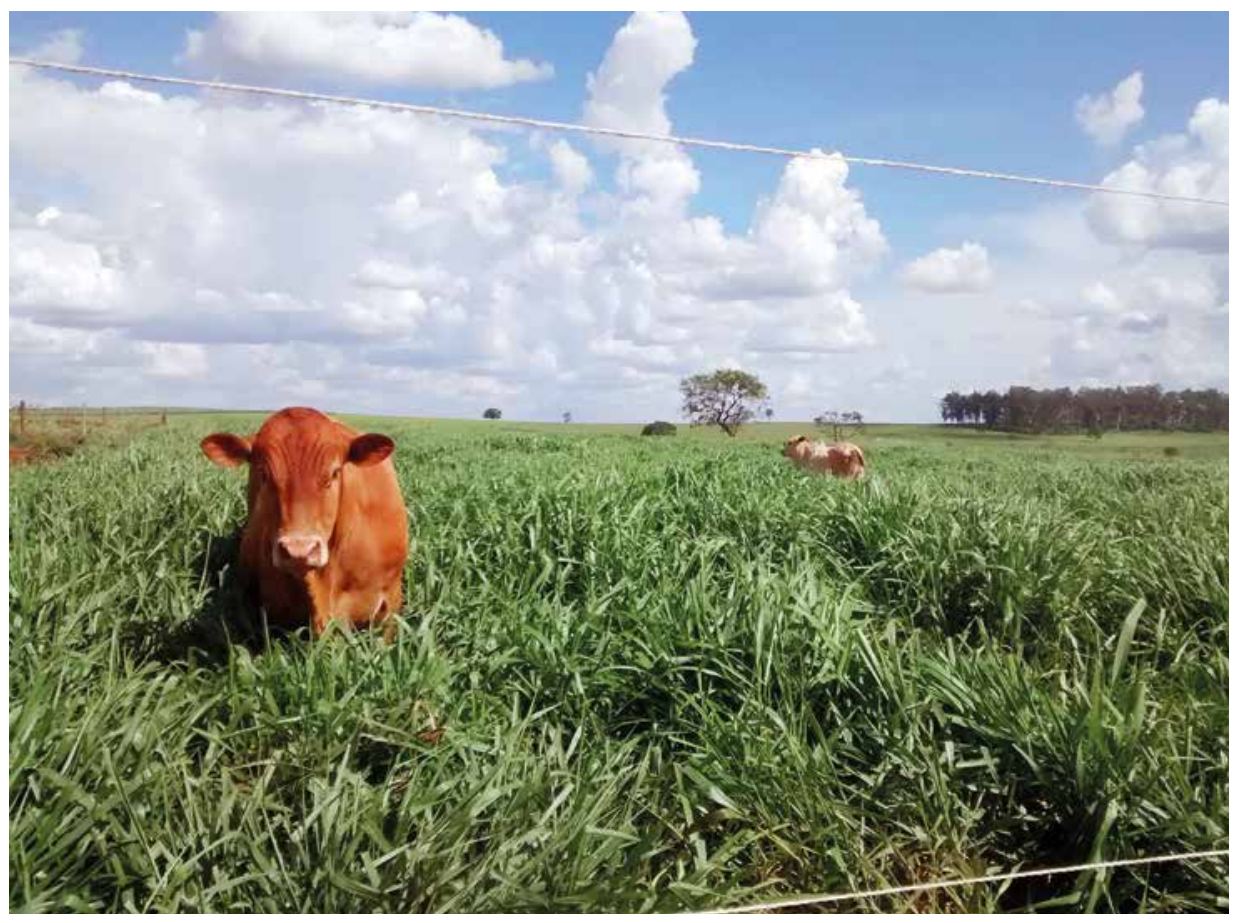

Figura 4 - Pastejo de verão em um sistema integrado. Fonte: Acervo do autor. 


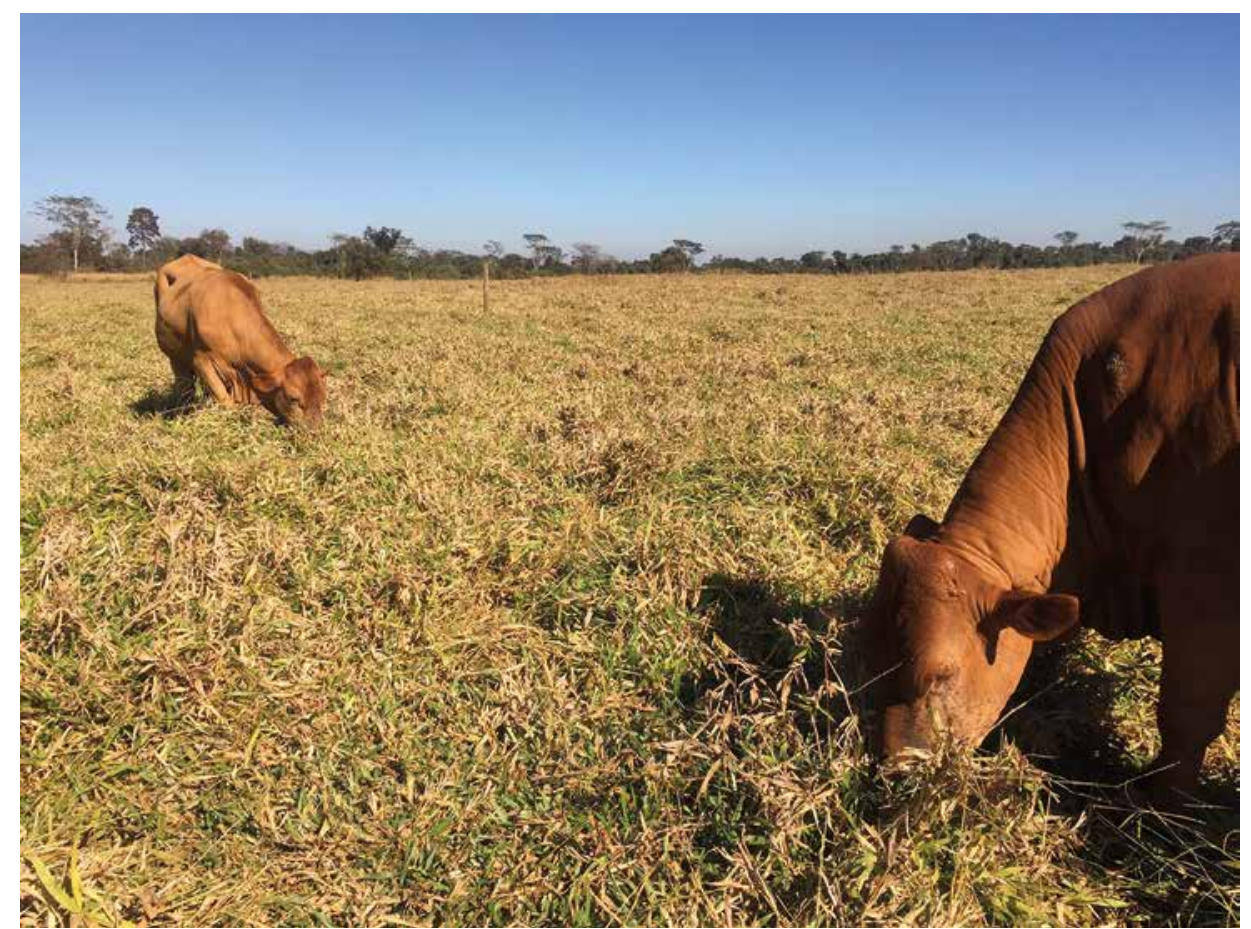

Figura 5 - Pastejo de inverno em um sistema integrado. Fonte: Acervo do autor.
As mudanças acima citadas podem parecer, a princípio, de difícil execução, contudo, quando comparadas ao aspecto gerencial, serão mais facilmente quantificadas. Possivelmente, o planejamento, a organização e a administração (das finanças e dos recursos físicos, naturais e pessoais disponíveis) representarão um entrave - dificilmente mensurável - para a adoção de sistemas de ILP, visto que $\mathrm{o}$ aspecto gerencial varia entre os sistemas de produção, dependendo do nível tecnológico e organizacional com o qual já se lida dentro da empresa rural.

Antes mesmo de implantar o sistema integrado, o produtor rural deve ter conhecimento de mercado. Por exemplo, o pecuarista terá que decidir qual cultura vegetal produzirá com base no objetivo que deseja atingir. No caso de se optar pelo milho, a pergunta é se a produção será destinada para grãos ou silagem. A opção de produzir silagem para alimentação animal na época das secas pode parecer promissora, desde que haja um planejamento em relação ao armazenamento desse produto e possíveis compras no caso de falta ou problemas na produção. Outra questão é decidir se a implantação da cultura vegetal acontecerá em apenas uma safra, com o objetivo de reformar o pasto, e, consequentemente, quantos anos durará a condução da pecuária. $\mathrm{Ou}$, ainda, se a produção do grão acontecerá na safra e safrinha, para que depois os animais sejam inseridos no sistema.

O planejamento deve ser constante, baseado nas tomadas de decisão a curto, médio e longo prazo. Por exemplo, caso a pecuária seja inserida no sistema, logo após a colheita da cultura vegetal, cercas, bebedouros e cochos devem ser implantados em tempo hábil. Nesse período, ações como a realização de amostragem de solo para tomada de decisão quanto a adubação e/ou técnicas de preparo do solo, ou tomada de decisão por sistema de plantio direto ou convencional, também farão parte da rotina, exigindo planejamento.

Inevitavelmente, conhecimentos sobre gestão financeira precisam fazer parte da rotina do produtor que decide assumir uma nova atividade em sua propriedade. Conseguir se organizar em relação aos custos e retornos de cada atividade, de maneira separada, facilitará a alocação de recursos e possibilitará afirmações acerca dos lucros e investimentos futuros.

\section{Considerações finais}

É necessário que pesquisas na área de sistemas de ILP sejam desenvolvidas por equipes multidisciplinares, capazes de demonstrar os benefícios e entraves da adoção e manutenção desse tipo de sistema de acordo com diferentes óticas (produtiva, ambiental, econômica e social).

A compreensão das teorias que podem embasar os possíveis resultados positivos dos sistemas de ILP em comparação ao monocultivo, bem como a abordagem dos entraves na adoção e manutenção desse tipo de sistema, se faz essencial. Dessa maneira, será possível enriquecer a discussão acerca da competitividade de sistemas de ILP, subsidiando a tomada de decisão e a adoção desse tipo de sistema em escalas comerciais. (c) 


\section{Referências}

ALMEIDA, R. G.; PEREIRA, M. A.; KICHEL, A. N.; COSTA, F. $P$. Planejamento e gestão de sistemas pecuários integrados com agricultura. In: SIMPÓSIO BRASILEIRO DE PRODUÇÃO DE RUMINANTES NO CERRADO, 3., 2015, Uberlândia. Anais... Uberlândia: UFU, 2015. Disponível em: <http://bit.ly/2paa3Ff>. Acesso em: 3 fev. 2017.

ANSELL, D.; FREUDENBERGER, D.; MUNRO, N.; GIBBONS, P. The cost-effectiveveness of agri-environment schemes for biodiversity conservation: a quantitative review. Agriculture Ecosystems \& Environment, Amsterdam, v. 225, p. 184-191, 2016.

COIMBRA, C. H. G.; PERINA, R. A.; FAUSTO, D. A. Análise econômica de um sistema de integração lavoura-pecuária. IPecege, Piracicaba, v. 1, n. 1, p. 63-80, 2015.

GAMEIRO, A. H.; ROCCO, C. D.; CAIXETA FILHO, J. V. Linear programming in the economic estimate of livestockcrop integration: application to a Brazilian dairy farm. Revista Brasileira de Zootecnia, Viçosa, v. 45, n. 4, 181-189, 2016.

GAO, Z.; FEATHERSTONE, A. M. Estimating economies of scope using profit function: a dual approach for the normalized quadratic profit function. Economic Letters, Amsterdam, v. 100, n. 3, p. 418-421, 2008.

LEMAIRE, G.; FRANZLUEBBERS, A.; CARVALHO, P. C. F.; DEDIEU, B. Integrated crop-livestock systems: strategies to achieve synergy between agricultural production and environmental quality. Agriculture, Ecosystems \& Environment, Amsterdam, v. 190, p. 4-8, 2014.

MACEDO, M. C. M. Integração lavoura-pecuária: o estado da arte e inovações tecnológicas. Revista Brasileira de Zootecnia, Viçosa, v. 28, n. esp., p. 133-146, 2009.

MARTHA JÚNIOR, G.B.; ALVES, E.R. de A.; CONTINI, E. Dimensão econômica de sistemas de integração lavourapecuária. Pesquisa Agropecuária Brasileira, Brasília, DF, v. 46, n. 10 p. 1117-1126, 2011.

SALTON, J. C.; MERCANTE, F. M.; TOMAZI, M.; ZANATTA, J. A.; CONCENÇO, G.; SILVA, W. M.; RETORE, M. Integrated crop-livestock system in tropical Brazil: Toward a sustainable production system. Agriculture, Ecosystems \& Environment, Amsterdam, v. 190, p. 70-79, 2014. 